\title{
Impact of Technology and Innovation on Adaptation of Architectonic Tradition for a Sustainable Future in the Middle East
}

\author{
Isra’a S. Fardous and Amar Bennadji \\ Scott Sutherland School of Architecture and Built Environment, Robert Gordon University
}

\begin{abstract}
Over the last three decades, the Middle East (ME) region has experienced rapid economic and infrastructure transformation. Most of the dwelling places have fully adopted western architectural trends ignoring both the cultural and environmental fundamentals of the region. The paper is incorporated with a Ph.D. research, it is cognizant of the fact that socio-demographics has changed over the years. Large cities in the region have experienced massive population growth which has made traditional architectural (TA) less suitable. This study is focused on identifying how recent innovation and technologies can be used in the adaptation of architectonic traditions. Seeking to identify how the inherent sustainability characteristics of TA can be integrated with modern architectural studies for cultural relevant and sustainable dwellings in the ME. An investigation in houses in Riyadh City, Saudi Arabia where the climate is mostly hot and arid will serve as the case study for this research because of its strong history in TA coupled with proliferation of western architecture. Research will utilize a qualitative data because it is inclusive of situational descriptions, events and observed behaviors. It will enable findings based from the participants view to cultural existence and change, and meanings important to them. Moreover, researcher will rely on the themes as the main backbone on what the study is trying to bring out. Thus, will ensure findings end up with what is appreciated for environmental housing application not only based on climate control but also based on other psychological and visual components.
\end{abstract}

Key words: Environmental traditional architecture, thermal comfort, transitional architecture and well-being.

\section{Introduction}

Human life future existence has of late exclusively remained dependent on technology. Societal behavior is largely shaped by technology particularly its shape and change of direction. Society lifestyle behavior has largely been affected by some of these rapid technological changes. Technological effects are felt in every level of society. Modern building technology is a perfect example of effects of technology [1-6]. Architecture and interior design have shifted their focus from traditional technological perspective to a modern technological setting.

In this regard, the researcher aims to address the following research questions:

Corresponding author: Amar Bennadji, Dr., research fields: environmental design, energy consumption control and building performance and visualization. E-mail: i.s.a.k.fardous@rgu.ac.uk.
1. What is the importance of the architectonic features in building residential in the Middle East

2. How can technology and innovation be used to reach a sustainable level of thermal comfort?

3. Is there a good or bad adaptation in transitional or modern spaces despite high temperatures

4. Do people still appreciate the traditional architecture?

5. Which technology can aid in improved sustainability in the Middle East to aid in improved levels of thermal comfort with the collaboration of old environmental architecture?

\section{Recent Technologies}

Some of the most important and effective sources guiding the development of styles and types of buildings is technology and innovative building materials. Architects have used these materials for 
centuries and the knowledge needed to work and apply them has moved from master to novice. There is a big need for technology and innovation in building features to be driven towards sustainability. Many designers, architects, manufactures, customers and building users are very interested in the field of technological innovation.

Innovation can result in faster, safer and less costly ways of executing things but can also result in costly mistakes. Nonetheless, the construction industry in general has a bad reputation for innovation. Most of the times, it is faulted of being slow at adopting new technologies [7-13]. The main drivers of the 21st century and the new economy are transcendent technologies. The most advanced innovative materials and building technologies have been created in these fields of application:

- Biomaterials - structures and materials that are fire retardant

- High-throughput or combinatorial methods cement and other building materials

- Nano-composites, tissue engineering and nanoparticles.

- Surface and Interface Characterization - Sensor materials and systems

- Thin films - magnetics, electronics, photonics materials

Outdoor air temperature is affected by a number of factors. Environmental designs are made in a way that they just perform the same function performed by indoor cooling techniques. Bioclimatic design principle test on the cooling effect of outdoor spaces in hot regions was conducted and the parameters précised as follows:

\subsection{Materials of the Space}

Bentz and Peltz [7]; Berry et.al [8] all believe that materials play a large role in determining outdoor air temperature. Computer simulations proved to be ineffective in giving out outdoor material library. The soft wares selection of the material range is also ineffective. The materials selected by ENVI-Met' software were as follows: concrete, brick road, asphalt road, sandy soil, deep water or granite pavement. If the researcher had to come up with his own specific materials through research, the above materials would prove to be inefficient. This aspect forced the researcher to ignore material parameter from the present study.

\subsection{Geometry to Width Ratio}

This is the most effective factor in controlling air temperature. The designer is able to create pleasant space using shade and wind more than any other factor such as space inclusion and shape. The geometry of the space in terms of height to width ratio is considered the most effective factor controlling the impact of geometry on air temperature. The manipulation of such factor gives the designer the chance to create pleasant spaces through shade and wind in spite all the other geometry factors such as space enclosure, and shape.

Geometry: Space Composition (Surrounded, Semi Surrounded)

Space composition on the air temperature remains dependent on all other factors such as Height: Width ratio of form, where it is impossible to study it independently, and an aspect that necessitates its inclusion.

Geometry: Form of the Space (Circular, Rectangular, Linear, Staggered)

Previous studies conducted to investigate on the effect of space from the microclimate revealed that, space plays a huge role on temperature change.

Size of the Space (Usually Represented in Volume)

According to Bentz and Peltz [7] size of the space factor often has very minimal impact which makes it insignificant to be tested; it is due to this aspect that the researcher excluded it from the current study. Microclimate impacts seem to vary greatly according to the different ratios volume in space.

Orientation of the Space 
Orientation proved to have significant impact on the cooling effect. This orientation seem to have minor effect on its own, orientation effect still affords to place in position of proper space geometry.

\section{Vegetation}

Vegetation is overwhelmingly believed to be the most influential factor in all the bioclimatic principles. This study also considers vegetation as a crucial parameter in obtaining these studies goals.

\section{Water Features}

Cooling sensation of the wind is rapidly increased when water features are added from the space during hot dry climates. This normally applied in such climates. This study excluded some water elements such as fountains mainly because they are considered to increase the damp sensation of arid climate.

\section{Sheltering Elements (Canopy)}

As opposed to testing manmade the parameters the current study will mainly specialize in natural bioclimatic parameters. The main reason for avoiding manmade parameters is due to its need for much more research. Previous studies tried to give actual prescription of the cooling level in each of the parameters tested, something that necessitated the researcher to adopt this process in the current study.

\section{Middle East Architectural Values}

Over the past two decades, Middle Eastern Arab cities have experienced major change. Importing Western architectural ideas and scientific progress have brought about major architectural changes based on modernization. In many cases, the region has been required to modernize fast, causing a sharp battle between traditional values and imported ideas. Some of the major movements in the Middle East can be credited to the conflict between borrowed Western ideas and traditional values. The largest architectural perspectives in some of the prominent cities in Middle East like Abu Dhabi have a transition of both Middle East and Western designs. The architectural expression and language is mainly Western. The main reason that Western practices and styles have become prevalent is the solid relationship between Western architectural prestige, style, improvement and being ultramodern. Accordingly, traditional architectural practices are viewed as outdated and of less prestige.

For centuries, innovations and historic changes as modern aspects have been part of society. As technology advances and develops, practices in society also change. Traditional architectural; practices have also changes with time to reflect varying tastes. Nonetheless, the speed of globalization and acceptance of foreign methods has resulted in a scenario where social theory must be rethought with regard to culture. Architects in the Middle East are building structures depicting their visions and dreams although they lack a national relevance and cultural identity $[10,11]$. There is a growing trend of building structures that abide by global best practices although they do not have truth and character.

Many architectural academics and architects argue that architecture should be standardized and globalized. This view is propagated by global media endorsing by creating global best practices that result in similarity, which has been described as tasteless and unexciting. In the Middle East, traditional architectural practices are created and premised on decorative aesthetics, an important aspect that Western architecture do not have. Nonetheless, it does not insinuate that imported styles should be disregarded; rather, taking the best of both would be perfect to create progressive buildings for the quickly modernizing region. Middle-Eastern architects find themselves in a disputed situation between imported architectural styles and local cultures [10].

\section{Traditional vs. Modern Architecture}

In conventional building construction technology, the main method of architectural design that existed was wood-framed, stone-stacking and mud bricks structures. Compared to latest architectural design, this early method of design can only be described as simple and pure. However with the invention of 
technology, human beings slowly begun associating themselves was seen as homogenous building. Technology allowed the architectural design to look similar to its surrounding. Architects and designers were now forced to rely on their creative thinking to fill the newly created demand. Most of the designs were now based on creativity guided by technological inventions. Differentiating of one building from another was now an easy task for visitors as well as its elements thanks to the new elements of designs. There is a decrease in buildings visual aesthetics mainly due to limitation of building materials as everything continues to change. Cutting edge inventions and futuristic forms and shapes appearance is now possible due to creation and development of new building materials and technologies.

Technology has enabled discovery and manufacturing of new building materials and structures globally. Applying architectonic tradition to construct new buildings now remains the main critical task for architects globally. Perhaps this explains why most these architects become so much attached to visual appearance. Discovery of new forms of technology to coincide with the original design idea has largely remained dependent on the use of technology among most architecture. Visual aesthetics design of building is crucial in creating a perfect design condition as opposed to a good feeling space. Compared to other senses, visual sense continues to attract high human attention. There is a constant reduction and restriction of current architecture going by this trend. There is a constant diminishing strength between our bodies and space mostly due to lack of other senses. This is due to the fact that human being experience on space and environment remains largely dependent on their senses and not on their visuals. There is also a high increase in architecture image compared to experience. However, it's important to understand that products of architecture image only offer visual consumption and cannot be used to formulate long term solutions. There is need for pragmatic solutions to these problems.

\section{Technology and Innovation}

21st century adopted new change through the introduction of smart technologies for more sustainable materials and features. The level of functionality has significantly been increased through the introduction of diverse building features that also promote sustainability. There is a complete new face with the introduction of smart materials in building technology. These materials form an important part of smart structural system with the capability to sense its own environment. Smart materials have been in some cases referred to as living systems. No one focuses any more on providing traditional partition between Material Science and Architecture as this is no longer considered in construction industry technology. Sustainable construction which also refers to green construction or green building can simply be described as a system of construction which brings together structures and application process that are environmental friendly and resource efficient in the whole construction cycle.

Architectural evolution is mainly guided by the innovative building materials and technologies. These have continued to dominate the entire building history in mankind's existence. There are enormous products of building materials that are continuing to capture the market mostly due to constant innovations that we continue to experience. Designers have different distinctive applications to choose from with new materials introduction [13]. Without a doubt, technology is a prevailing and clear product of the advanced and creative gifts of humans. Thus, it can be listed as one of the aspects of the manifestation of the essence of humans. In this case, technology is not perceived to endanger human life. Instead, it is considered an opportunity and instrument of improving and easing human life. The process of utilizing technology is regarded as a magnificent and ultimate achievement. 


\section{Collaboration of Modern Architecture and Traditional Values/Designs}

The advancement of technology and fast urbanization has resulted in increased standardizations of houses and other built settings. Accordingly, human habits have been deprived of their cultural and local identity over the years. In the modern age, similar materials, building methods and styles are used the world over notwithstanding the tradition and history. Nonetheless, stakeholders have taken efforts in the last few years using conferences and symposia to change this trend.

Communities are gradually looking for strategies to create equitable and more sustainable cities. Cities all over the globe are being carefully observed by architects, economic geographers and social scientists with the aim to understand how developing technologies are driving worldwide spatial and economic growth. Besides practitioner interest in the developing global economic and architectural model, there has been major academic interest. Scholars [13] are constantly looking for strategies and ways to promote sustainable city development. This includes critically analyzing current practices considering both negative and positive aspects of modern and traditional architecture approaches. For majority of scholars, the solution is in integrating and effectively coordinating between modern and traditional approaches. This part critically analyzes studies on the potential collaboration between traditional and modern architectural values while finding gaps in past studies. The researcher conducted 20 interviews from residential occupants and summarized the main findings as follows:

1. What you like the current environment in your house to be like?

Figure 1 above discloses how the respondents prefer the environment (in number of people) to be like in their houses. The highest number of respondents (12) said that they would like the environment to be cooler, with 5 respondents who liked no change to the environment followed with 3 who would like the environment to be warmer.

2. How do you feel about air humidity at the moment?

Figure 2 above discloses the current sensation of the respondents (in number of people) when asked how they felt about air humidity. The highest number (6) of respondents said that the air humidity was dry. Respondents who felt that air was very humid and okay followed with 5 for each category. Respondents who felt that the air was humid were 2and 1 respondent felt that the air humidity respondent was too dry.

3. How do you feel about air flow/ ventilation in your residence?

Figure 3 above discloses the current sensation of the respondents (in number of people) when asked how they felt about air flow in their residence. The highest number of respondents (11) said that the air humidity was okay. Respondents who felt that air flow was stale were 3 and those who felt that there was little wind were 4 . The other remaining 2 respondents said that the airflow was windy.

4. Do you think the thermal environment can be improved in your residence using architectonic features?

Figure 4 above discloses the current sensation of the respondents (in number of people) when asked whether the thought thermal environment can be improved in your residence using architectonic features. Nineteen respondents said yes, with only one saying no.

5. In your opinion, what environmental circumstances would be thermally comfortable for residential houses?

Twelve of the interviewees suggested that adding shading areas and more zoned gathering seating areas would allow students to sit outside comfortably. Four agreed that they need shaded spaces because when temperatures are high it is uncomfortable. Four further added that a space with cross ventilation is also important and adequate shading has the potential for breezes during hot temperature. 

for a Sustainable Future in the Middle East

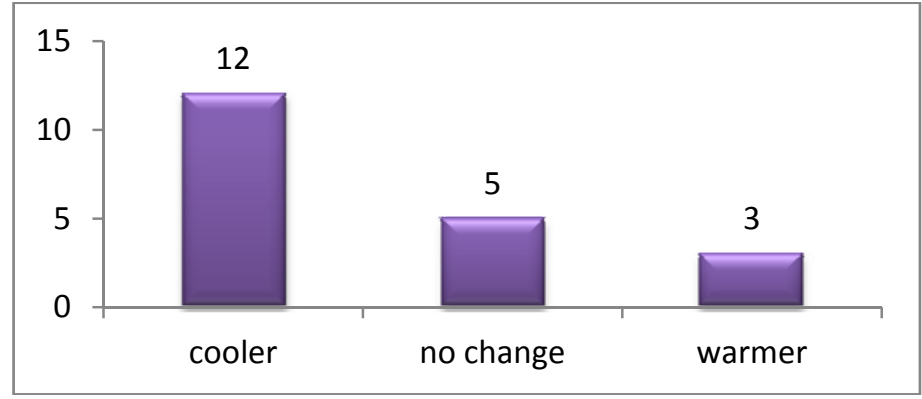

Fig. 1 Preference of environment.

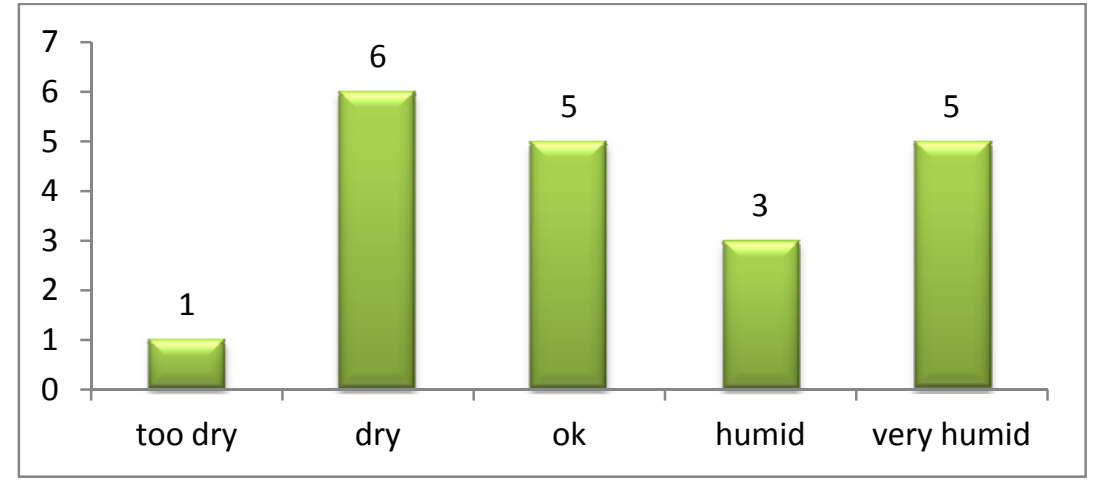

Fig. 2 Humidity.

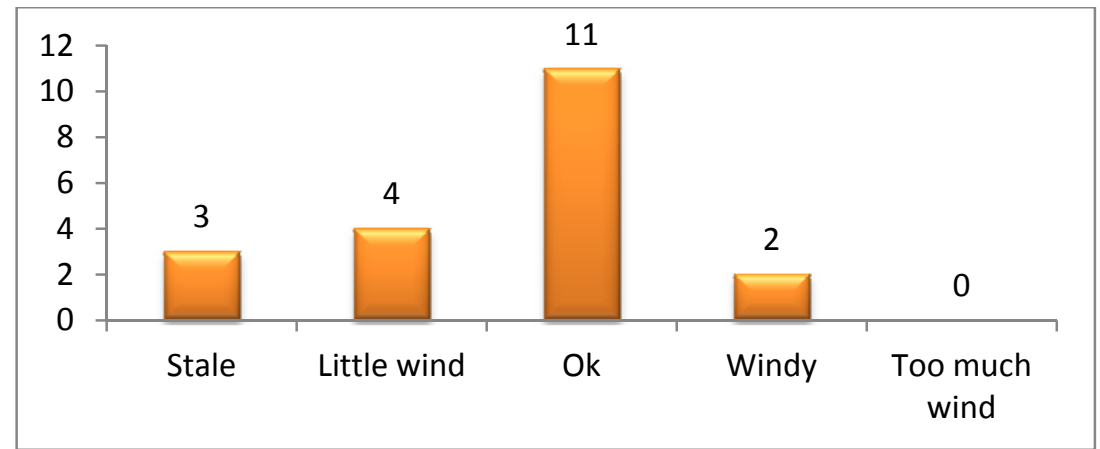

Fig. 3 Sensation.

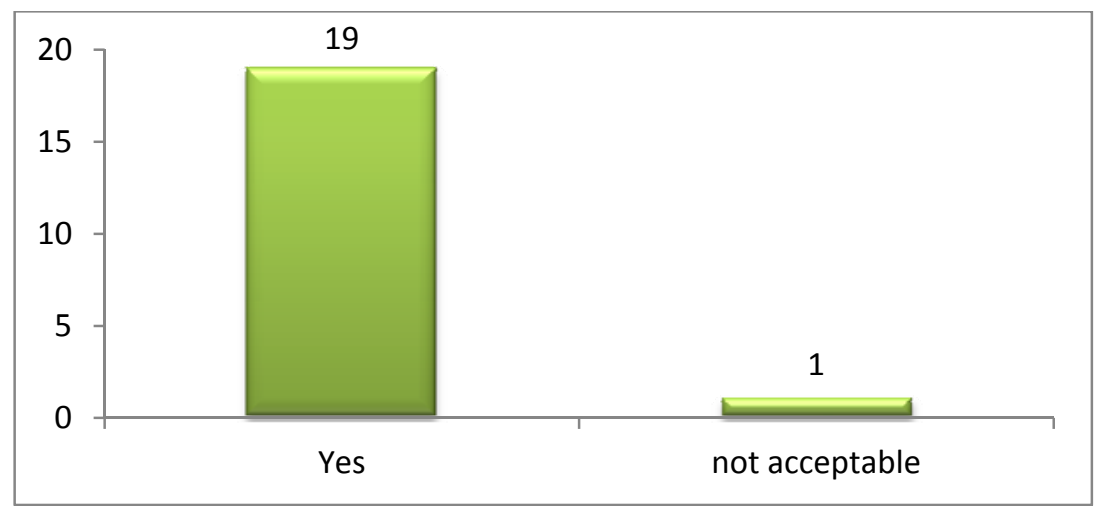

Fig. 4 Current sensation. 


\section{Typologies Data}

Three different spaces were considered, that is the outdoor space, living room and pool area as shown by figures 5, 7 and 6, respectively. The application of the Riyadh stone which is sustainable material were used to insulate the heat was an important architectonic feature used for the walls. The data presented in this paper was collected from Landform House; a private house designed by "the Other Dada Integrated Architecture Lab”

The temperatures in the outdoor spaces were particularly highest between April to October (27.9-27.3) and lowest during December and January which had 18.1 and 17.7. The month of July experienced
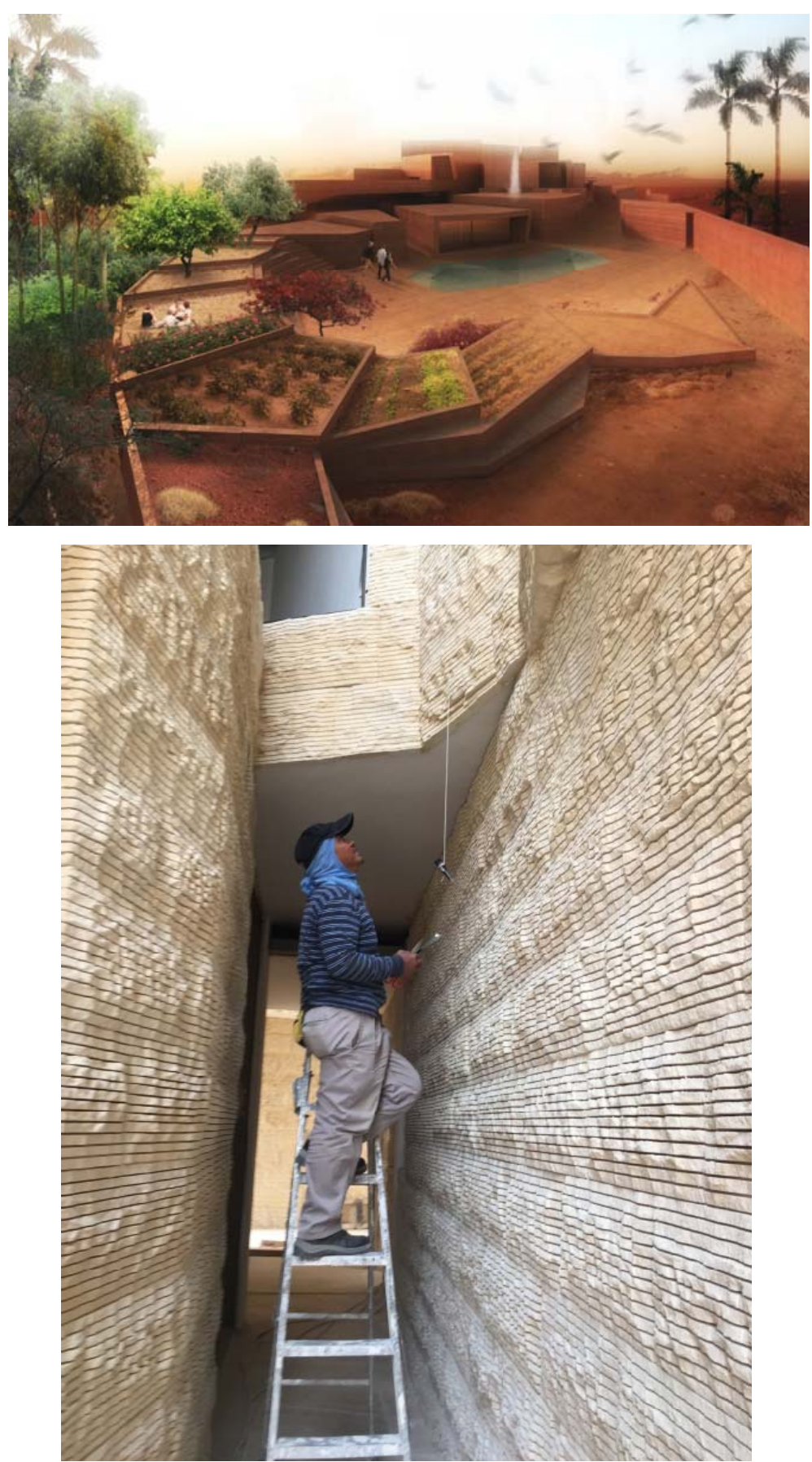

Fig. 5 Landform house outdoor. 


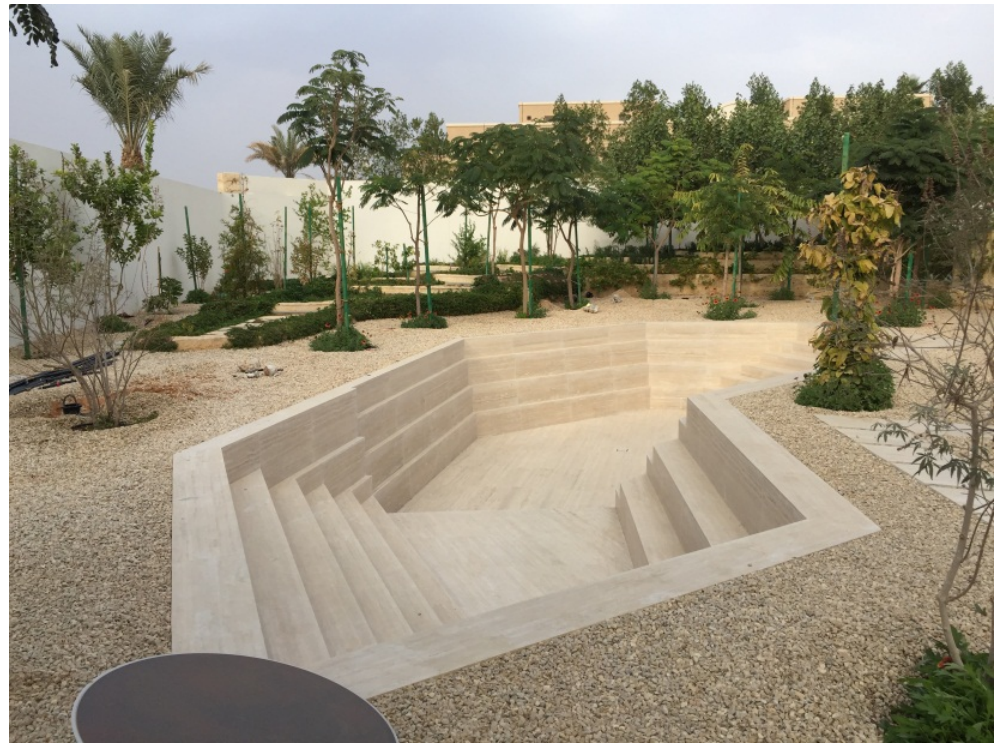

Fig. 6 Pool area space.

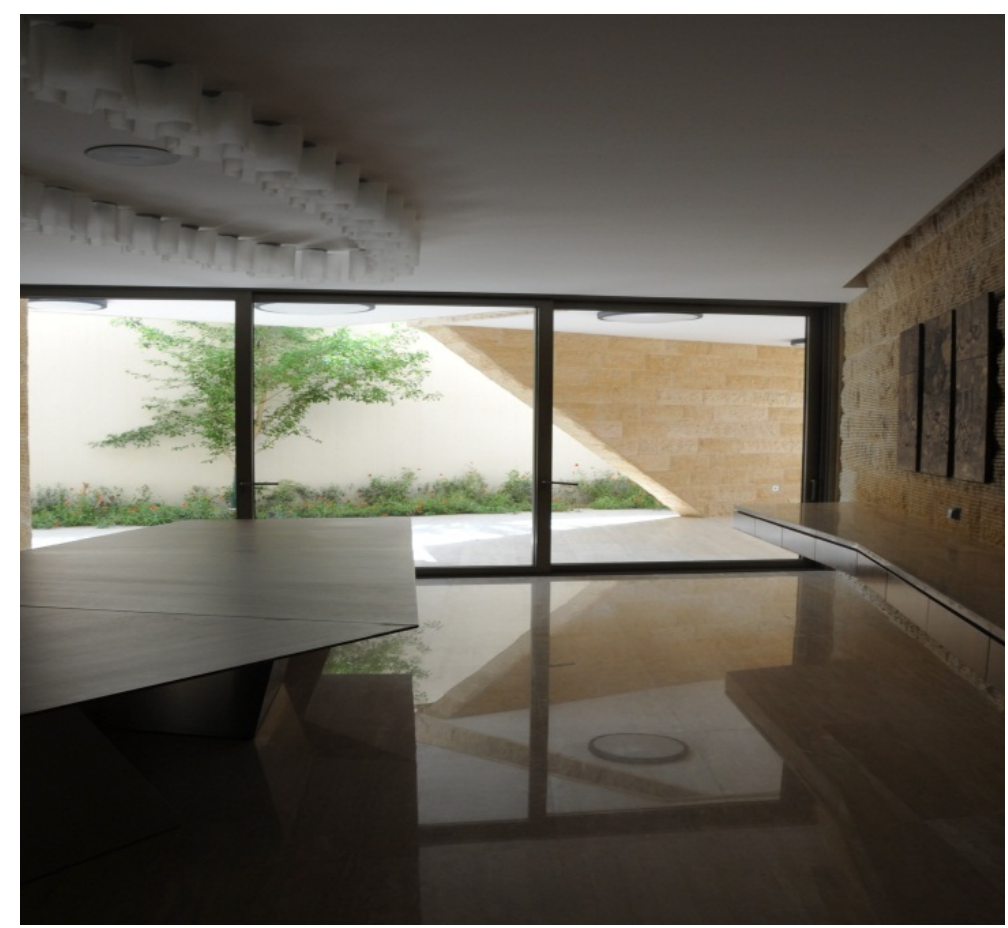

Fig. 7 Living room space.

Table 1 Outdoor climate data for landform houses from three different points of measurement (temperature-dew pointhumidity.

\begin{tabular}{|c|c|c|c|c|c|c|c|c|c|c|c|c|}
\hline \multicolumn{13}{|c|}{ Outdoor climate data for landform houses } \\
\hline Month & Jan. & Feb. & Mar. & Apr. & May & Jun. & Jul. & Aug. & Sep. & Oct. & Nov. & Dec. \\
\hline Average temp & 17.7 & NA & NA & 27.9 & 34.6 & 37.3 & 38.9 & 38.2 & 34.0 & 27.3 & 21.4 & 18.1 \\
\hline $\begin{array}{l}\text { Average } \\
\text { humidity }\end{array}$ & 36.0 & NA & NA & 36.3 & 17.1 & 10.8 & 11.9 & 13.0 & 16.8 & 18.0 & 34.8 & 46.2 \\
\hline $\begin{array}{l}\text { Average dew } \\
\text { point }\end{array}$ & 2.0 & NA & NA & 10.1 & 4.4 & 0.8 & 3.1 & 3.6 & 4.3 & 0.3 & 2.6 & 6.0 \\
\hline
\end{tabular}


the highest temperatures at 38.9. Humidity was highest for December, April and January with 46.2, 36.3 and 36.0 , respectively. June had the lowest humidity at 10.8 . For Average dew point, during the month of October it was lowest at 0.3 and highest for the month of April with 10.1 .

\section{Conclusions and Recommendations}

When asked on what design approaches can be used in to improve thermal comfort the interviewees suggested the following approaches:

(1) Change the flooring material as it becomes very hot during the warm seasons. Put one that has low thermal storage capacity;

(2) Provide for mechanical ventilation such as fan as it is the best way to minimize the humidity;

(3) Increase natural shadings (trees);

(4) Fabric shading is also preferable to hard shading devises. Fabric can be opened and closed depending on the time of day and season;

(5) Allow for adequate airflow;

(6) Provide low-energy fans in high-use areas.

In the modern age, the earth's resources are being used at an unsustainable rate. Using architectonic features which can be made possible using smart technologies it is possible to achieve optimum thermal comfort for the residential houses. Architectonic features are more applicable with the extreme heat. People might be more comfortable with heat or humidity when natural ventilation are implemented as opposed to use of mechanical air conditioning. In conclusion, technology and innovation can be intertwined on adaptation of architectonic tradition which can result in a sustainable future in the Middle East.

\section{References}

[1] Aina, Y. A., Al-Naser, A., and Garba, S. B. 2013. Towards an Integrative Theory Approach to Sustainable Urban Design in Saudi Arabia: The Value of GeoDesign.

[2] Al Surf, M., Susilawati, C., and Trigunarsyah, B. 2013. "Integration of Saudi Arabia's conservative Islamic culture in sustainable housing design.” In Proceedings of the 19th CIB World Building Congress, pp. 1-13. Queensland University of Technology.

[3] Al-Hassan, A. H., and Dudek, S. J. 2008. "Promoting Sustainable Development in Arabia through Initiating an Arab Architecture Accrediting Board.” Transactions 5 (1): 71-89.

[4] Al-Hathloul, S., and Mughal, M. A. 2004. "Urban Growth Management-The Saudi Experience.” Habitat International 28 (4): 609-23.

[5] Al-Jamea, M. 2014. "Towards Social and Cultural Sustainability in the Designs of Contemporary Saudi Houses.” Int J Sustain Hum Dev 2 (1): 35-43.

[6] Behzadfar, M., and Monam, A. 2011. "The Impact of Sky View Factor on Outdoor Thermal Comfort." Armanshahr 5 (2011): 23-34.

[7] Bentz, D., and Peltz, M. A. 2011. "Thermal Properties of High-Volume Fly Ash Mortars and Concretes.” J. Build. Phys. 34 (3): 263-75.

[8] Berry, R., Livesley, S. J., and Aye, L. 2013. “Tree Canopy Shade Impacts on Solar Irradiance Received by Building Walls and Their Surface Temperature.” Build Environ 69: 91-100.

[9] Dada, A. 2013. 3 Case Studies Comparative Analysis, Landform House: theOtherDada.

[10] Ghazizadeh, S. N., Monam, A., and Mahmoodi, A. S. 2010. "The Impact of the Architectural Design on the Thermal Comfort of the Outdoor Spaces in Residential Complexes.” Honar-ha-ye-Ziba 42 (2010): 59-70.

[11] Morakinyo, T. E., Balogun, A. A., and Adegun, O. B. 2013. "Comparing the Effect of Trees on Thermal Conditions of Two Typical Urban Buildings.” Urban Clim. 3: 76-93.

[12] Park, M., Hagishima, A., Tanimoto, J., and Narita, K. 2012. "Effect of Urban Vegetation on Outdoor Thermal Environment: Field Measurement at a Scale Model Site.” Build Environ. 56: 38-46.

[13] Shahidan, M. F., Jones, P. J., Gwilliam, J., and Salleh, E. 2012. “An Evaluation of Outdoor and Building Environment Cooling Achieved through Combination Modification of Trees with Ground Materials.” Build Environ. 58: 245-57 